\title{
Visualizing the Alliance Network Structure of Service Industries
}

\author{
Rahul C. Basole, PhD \\ Accenture AI \\ rahul.basole@accenture.com
}

\begin{abstract}
A growing body of research focuses on the structure of interfirm value co-creation. Despite this emphasis, little is known about the variation in interfirm collaboration across different service industries. Building on prior work in service value networks and business ecosystems, we analyze the structural characteristics of 11 service industries using a data-driven visualization approach. We first examine the alliance network structure of each service industry individually and differentiate the nature of collaboration using an exploration/coopetition lens. Second, we examine service industries integratively, thereby exploring the extent to which service industries are converging and traditional industry boundaries are blurred. Our results reveal significant structural differences in alliance network structures between service industries as well as diverse value co-creation orientations. Our macro analysis reveals an overall core-periphery structure and different service industry coupling levels, with actors in the ICT industry playing a particularly central role across subclusters. We frame our findings in terms of industry robustness, openness, and embeddedness. We conclude the paper with theoretical and practical implications for understanding and managing service ecosystems and suggest future research opportunities.
\end{abstract}

\section{Introduction}

In today's global business environment, no firm is an island [1]. Value is co-created and delivered by a multitude of firms [2, 3, 4]. In fact, firm success and survival depends on the formation and fostering of interfirm relationships with suppliers, customers, complementors, and even competitors [5]. Moreover. interfirm collaboration can enable firms to not only create new value offerings, but also access markets, accelerate innovation, and mitigate risks [6].

Given the tremendous benefits it is not surprising that the study of interfirm relationships has been pervasive in the strategic management and organizational science literature over the years $[7,8,9,10]$. One of the most common forms of interfirm relationship include alliances [11, 12]. The majorities of studies on alliances have typically focused on asset-heavy, product-oriented industries, such as biotechnology, electronics, industrial, pharmaceuticals, and manufacturing $[13,14,15]$. Yet, as many economies are becoming more service-centric, an examination of interfirm collaboration for service industries is needed $[16,17]$. Notable prior work include [18, 19, 20, 21, 22]

Inspired by seminal studies by [23, 24] on the structure and performance of industries, we examine the topological characteristics of service industries. Specifically, our study focuses on quantifying, visualizing, and then interpreting the structural characteristics of alliance networks across different service industries in terms of robustness/resilience, openness, and embeddedness. We operationalize these constructs using graph theoretic metrics. These metrics enable us to describe how each industry is organized, how it may shield itself from possible disruptions, and what models of value creation it uses. Next, following the perspective that industries are increasingly converging and co-dependent on each other, we extend our analysis to examine all service industries jointly. In doing so, we are able to discern the relative importance of each industry to others and the overall interconnectednesss of service value creation.

The implications of this study are multifold. By taking a service-centric industry lens on interfirm collaboration, we provide further evidence of the increasing interfirm complexity across all service industries. Second, alliance structures reveal different structural patterns across industries, indicating distinct intra-industry dynamics at play. Third, not surprisingly our results reiterate the particular importance of the ICT industry to all service sectors. As more service industries become increasingly digitized and embrace promising new technologies, such as artificial 
intelligence and distributed ledgers, building the right relationships with ICT industry partners is critical.

The remainder of this study is organized as follows. Section 2 presents our research methodology, including data curation, network construction, metrics, and visualization. Section 3 describes the results of our exploratory analysis. Theoretical, managerial, and methodological implications are discussed in Section 4. Section 5 concludes the study.

\section{Methodology}

Following prior work, we use a multi-stage approach to identify, analyze, and understand the alliance network structure across service industries (see Figure 1).

\subsection{Data}

We identify service industries using the classification approach suggested by [25]. However, since International Standard Industrial Classification of All Economic Activities (ISIC) codes are not used by our primary data source, we had to convert them into Standard Industrial Classification (SIC) codes using a multi-step concordance approach. Specifically, we developed custom scripts to first map ISIC.Rev $4^{1}$ to NAICS 2017 Codes $^{2}$ and then NAICS 2017 to SIC codes $^{3}$. The results of this mapping are shown in the online appendix (provided upon request).

Next, we extracted all alliances formed by firms with a primary SIC code from our list between 1999-2018 from Thomson Reuters SDC Platinum Database (henceforth SDC). SDC is a commonly used data source for the study of strategic alliances and industry networks in strategic management and organization science and is widely regarded as one of the most comprehensive databases of its kind [12]. Curated from SEC filings, SDC includes information on many different types of collaborative relationships, including strategic alliances, supply, research and development (R\&D), marketing, licensing and manufacturing. We include all active relationships between 1999 and 2018 for companies with a primary SIC in the corresponding service industry. We chose the last twenty years as our focus timespan as it includes periods of emergence, stagnation, and growth in the services industry. We exclude alliances that were terminated during the period.

For each alliance, we extracted the participants'

\footnotetext{
${ }^{1}$ https://unstats.un.org/unsd/ classifications/Econ/Download/In \\%20Text/ISIC_ Rev_4_publication_English.pdf

${ }^{2}$ https://www.census.gov/eos/www/naics/ 2017NAICS/2017_NAICS_Manual.pdf

${ }^{3}$ https://www.osha.gov/pls/imis/sic_manual. html
}

names, their primary SIC codes, as well as location, agreement type(s), date announced and effective, and textual description. We used text analytic techniques to identify alliances that explicitly mention "services" in the description. To identify whether an alliance was of coopetitive or exploratory nature we used the approach proposed by [5]. If any one of the participant's SIC codes was not in the focal industry, then it was coded as exploratory; otherwise it was coded as coopetitive.

\subsection{Network Construction}

We construct a cumulative firm-level ecosystem network using a weighted adjacency matrix for each service industry as well as all industries integratively. An adjacency matrix is a square matrix with nodes (e.g., firms) as both rows and columns. The presence of an alliance between firms $i$ and $j$, denoted by $x_{i j}$, is coded as 1 , and 0 otherwise. Given that alliances may contain more than two firms, we constructed relationship edges between all firms in an alliance. An alliance with three firms, for example, therefore would generate three edges.

Entries in the matrix were scaled following the weighting scheme proposed by [26], who argued that the strength of interfirm relationship is determined by the amount of knowledge exchanged. Consequently, R\&D and marketing (5) were assigned the largest weight followed by technology transfer (4), supply chain, manufacturing, and OEM (3), and (exclusive) licensing (2). All other remaining alliance types were given a unit weight (1). For joint ventures, we looked into the alliance text of each agreement as suggested by [26]. If a joint venture was associated with another alliance type (e.g. R\&D), we coded it as that type. If no alliance type was identified, based on author consensus, we assigned it to the lowest unit weight. If an alliance consisted of multiple types (e.g., marketing and manufacturing), we selected the maximum value of relevant alliance type weights. We did not consider relational direction, resulting in an undirected multiplex graph.

\subsection{Metrics}

Following prior work [1], we computed several network-level metrics that describe the structural characteristics of a service industry. These include size (number of nodes), alliances (number of edges), average degree (the average number of alliances per firm), the average weighted degree (the average number of relationships per firm taken multiple relationships between firms into account), network diameter (the maximum number of hops between any two firms in the ecosystem), density (the ratio of total alliances and 


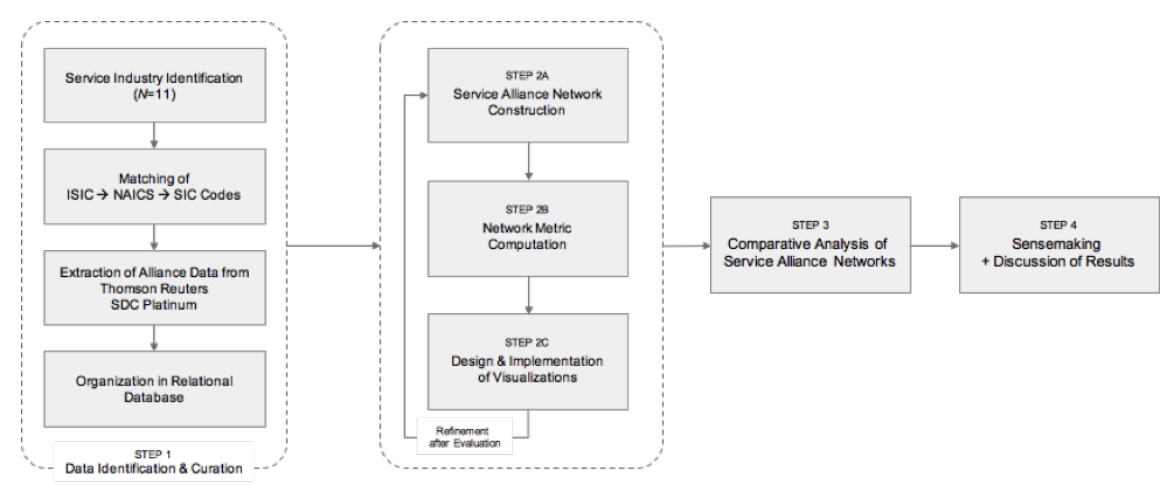

Figure 1. Multi-Step Research Methodology.

all possible alliances), average clustering coefficient (the average ratio of total alliances and all possible alliances among a focal firms partners), modularity (the number of components in the ecosystem), and the average path length (the average number of of hops between any pair of firms in the ecosystem) [27].

\subsection{Visualization}

Visualizations are a fundamental component of human learning and understanding and a key step in transforming data to knowledge [28]. Visualization can be used to explore, interpret and communicate data and aid decision makers with overcoming cognitive limitations. By mapping data to visual encodings, visualizations of ecosystems make the "what, why, how, and who" explicit. Prior work has provided important novel and complementary insights into the structure, dynamics, and strategy of industry networks and business ecosystems using visualization [29, 30, 31].

We use Gephi 0.92, an open- source software for visualizing and analyzing large network graphs, to graphically depict each service industry ecosystem [32]. Specifically, we use the force-directed Yifan $\mathrm{Hu}$ multi-level layout algorithm [33] to position nodes. A force-based layout is based on the idea that network entities are shaped by mechanical laws, assigning repulsive forces between nodes and attraction forces between endpoints of edges. The use of a force-based layout is particularly appealing when the motivating issue is to identify central or prominent nodes, peripheral actors, or clusters in an ecosystem. The Yifan $\mathrm{Hu}$ multilevel layout combines a force-directed model with a graph coarsening technique to reduce the complexity. We use the default initial parameter configuration. To ensure readability and aesthetics, we followed several visual design principles, including no node overlap and edge crossing minimization. In all our network visualization, node size is proportional to the firm's importance as measured by Betweenness centrality. To gain insight into the presence of subcommunities, we color encode nodes with the corresponding modularity class. We use a NoOverlap algorithm to space out nodes and address potential visual occlusion issues.

\section{Results}

Table 1 shows a summary of the structural characteristics of each service industry. The results show that service industries range in size from 1,555 (Public) to 35,299 firms (ICT), with an average of approximately 1.6 alliances per firm for the whole industry. When examining only the main component (the largest connected subgraph), the average degree ranges from 2.444 alliances in the health to 4.855 in the art service industries. The network diameter, or the largest distance between two firms in a service industry, is as small as 11 in estate and public to 28 in the professional service industry. The average path length is the smallest in Estate as well followed by administrative to largest in professional and health industries. The density, measured as the ratio between current and all possible alliances, is expectantly low. The average clustering coefficient, a proxy for how robust a network is, ranges from 0.297 (ICT) to 0.693 (Education).

With these high-level structural characteristics in mind, we turn to exploring the nature of the alliances in more detail. Table 2 provides a summary of the degree of coopetitive and exploratory alliances in the main component (Columns A and B, respectively) by service industry and the corresponding value-seeking orientation (Column $\mathrm{C}$ ), determined by examining the ratio of (A) and (B). The results show that five industries have a balanced value seeking orientation, namely Food, Finance, Professional, Education, and Art. Several industries are exploratory oriented, including Estate, 
Table 1. Structural Characteristics of Service Industries (1999-2018).

\begin{tabular}{|c|c|c|c|c|c|c|c|c|c|c|c|c|}
\hline & & & & & & & & Main Component & & & & \\
\hline & Alliances & Nodes & Edges & Nodes & Edges & Avg. Degree & Avg. Weighted Degree & Network Diameter & Density & Avg. Clustering Coefficient & Modularity & Avg. Path Length \\
\hline Food & 1,445 & 2,389 & 2,128 & $464(19.42 \%)$ & $589(27.68 \%)$ & 2.539 & 2.612 & 13 & 0.005 & 0.544 & 0.845 & 5.609 \\
\hline ICT & 30,305 & 35,299 & 32,889 & $14,991(42.47 \%)$ & $24,042(73.1 \%)$ & 3.208 & 3.329 & 21 & 0 & 0.297 & 0.78 & 6.005 \\
\hline Finance & 7,577 & 11,463 & 13,105 & $4,141(36.12 \%)$ & $7,816(59.64 \%)$ & 3.775 & 3.976 & 20 & 0.001 & 0.562 & 0.815 & 6.09 \\
\hline Estate & 1,289 & 2,298 & 2,065 & $314(13.66 \%)$ & $549(26.59 \%)$ & 3.497 & 3.618 & 11 & 0.011 & 0.697 & 0.801 & 4.494 \\
\hline Professional & 13,512 & 21,321 & 19,557 & $5066(23.76 \%)$ & $7861(40.2 \%)$ & 3.103 & 3.21 & 28 & 0.001 & 0.494 & 0.867 & 7.24 \\
\hline Administrative & 5,855 & 9,606 & 8,997 & $2,000(20.82 \%)$ & $3,319(36.89 \%)$ & 3.319 & 3.427 & 20 & 0.002 & 0.554 & 0.867 & 7.021 \\
\hline Public & 879 & 1,555 & 1,377 & $180(11.58 \%)$ & $297(21.57 \%)$ & 3.3 & 3.456 & 11 & 0.018 & 0.688 & 0.75 & 4.627 \\
\hline Education & 1,545 & 2,723 & 2,522 & $415(15.24 \%)$ & $784(31.09 \%)$ & 3.778 & 3.986 & 14 & 0.009 & 0.693 & 0.767 & 5.838 \\
\hline Health & 2,159 & 3,499 & 2,725 & $550(15.72 \%)$ & $672(24.66 \%)$ & 2.444 & 2.491 & 25 & 0.004 & 0.35 & 0.892 & 10.422 \\
\hline Art & 5,375 & 9,606 & 9,010 & $1,874(19.51 \%)$ & $3,184(35.34 \%)$ & 3.398 & 4.855 & 22 & 0.002 & 0.678 & 0.891 & 7.233 \\
\hline Others & 3,422 & 5,626 & 5,641 & $1,211(21.53 \%)$ & $2,457(43.56 \%)$ & 4.058 & 4.357 & 20 & 0.003 & 0.692 & 0.72 & 5.232 \\
\hline
\end{tabular}

Table 2. Degree of Coopetition/Exploration.

\begin{tabular}{l|lll} 
& (A) Coopetitive Alliances & (B) Exploratory Alliances & (C) Value-Seeking Orientation \\
\hline Food & $48.26 \%$ & $51.74 \%$ & Balanced \\
ICT & $61.55 \%$ & $38.45 \%$ & Moderately Coopetitive \\
Finance & $48.91 \%$ & $51.09 \%$ & Balanced \\
Estate & $40.82 \%$ & $59.18 \%$ & Moderately Exploratory \\
Professional & $47.47 \%$ & $52.53 \%$ & Balanced \\
Administrative & $16.61 \%$ & $83.39 \%$ & Strongly Exploratory \\
Public & $38.20 \%$ & $61.80 \%$ & Moderately Exploratory \\
Education & $44.47 \%$ & $55.53 \%$ & Balanced \\
Health & $52.30 \%$ & $47.70 \%$ & Weakly Coopetitive \\
Art & $45.59 \%$ & $54.41 \%$ & Balanced \\
Others & $39.85 \%$ & $60.15 \%$ & Moderately Exploratory \\
\hline
\end{tabular}

Public, and Others. The Administrative service industry has a rather strong skewedness towards exploratory value seeking activities. The arguably most dynamic service industry in our study is moderately coopetitive, suggesting a more independent, inward focus when considered alone.

Figure 2 shows the longitudinal evolution of alliance formation across service industries from 1999-2018. A breakdown by alliance type is provided in the online appendix (upon request). Broadly, it can be observed that alliance formation has been the strongest in the ICT industry, with a peak of 4,597 alliances formed in 2000. There has been a gradual decline in alliances from 2000-2010 but a significant jump back in the last few years. A similar pattern can be observed for the Professional industry. In the past few years (2015-2018) there appears to be a steady growth in alliances, with a local peak in 2017.

To understand the structural size and complexity of each service industry beyond aggregate statistics, we leverage a network visualization approach. For comparative purposes, Figures $3 \mathrm{a}-\mathrm{k}$ show a small multiple visualization of the alliance networks of each service industry. We differentiate nodes by within (blue) and outside (pink) of the focal service industry. Edges utilize interpolated color edges. To avoid visual clutter, we do not label the nodes. The visualizations reveal several topological differences. First, it can be clearly observed that the ICT industry is both large in size and much more connected than all other industries. We also notice several clear patterns with distinct ring-shaped structure in industries such as Food, Education, and Health. In many of the smaller industries, such as Food, Public, and Education, outside-the-industry firms (blue) appear to occupy prominent central positions. Each service industry, expect ICT and Finance, appears to have some distinct clusters as well.

Figure 4 shows an integrative, macroview of all firms and all service industries. Nodes are color-encoded by industry and sized by Betweenness centrality. There are several immediate observations that can be made. First, firms from all industries are almost randomly scattered across the entire service industry ecosystem with no clearly defined demarcation by industries. Second, while several clusters are apparent at the center and periphery, the industry composition of these clusters is quite diverse. Third, for each of the different clusters that are visible it appears that an ICT firm is quite prominent and centric to it (encoded as $\bullet$ nodes). Lastly, only peripheral clusters appear to be rather industry homogeneous, such as the healthcare (encoded as nodes) or professional clusters (encoded as o nodes).

Figure 5 shows an alternate visualization of cross-service industry value creation activities using a square matrix heatmap approach. The visualization indicates the propensity of a focal service industry to collaborate with another service industry. The darker the cell, the higher the collaboration intensity between the two service industries. Several interesting observations can be made. First, all service industries contain a significant amount of coopetitive relationships (as indicated by the diagonal). Second, almost all industries contain collaborations with firms from all other industries at least to a certain degree (the exception is health and food). Third, the largest service industry, ICT, predominantly forms alliance activities with itself confirming the finding that it is moderately coopetitive. It collaborates most closely with the administrative, professional, and finance services industries. It forms least number of alliances with the public, estate, and food services sector. Both the food and estate service industries collaborate the most with the art industry. The health service industry has very weak collaboration with the food, estate, and public service industry. Notably absent are collaborations between the health service industry and the food services industry. 


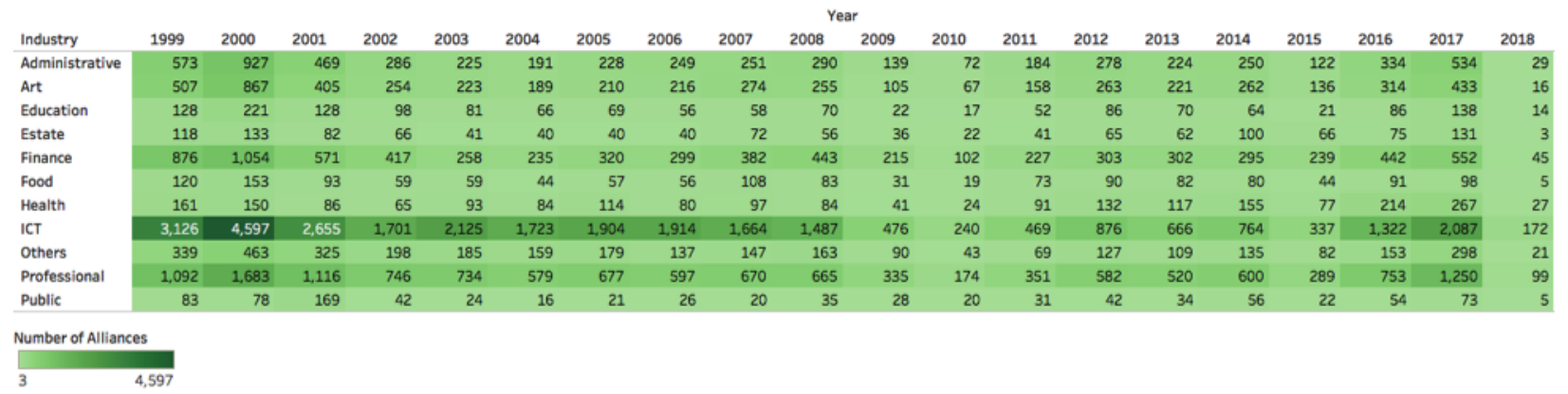

Figure 2. Alliance Formation across Service Industries (1999-2018).

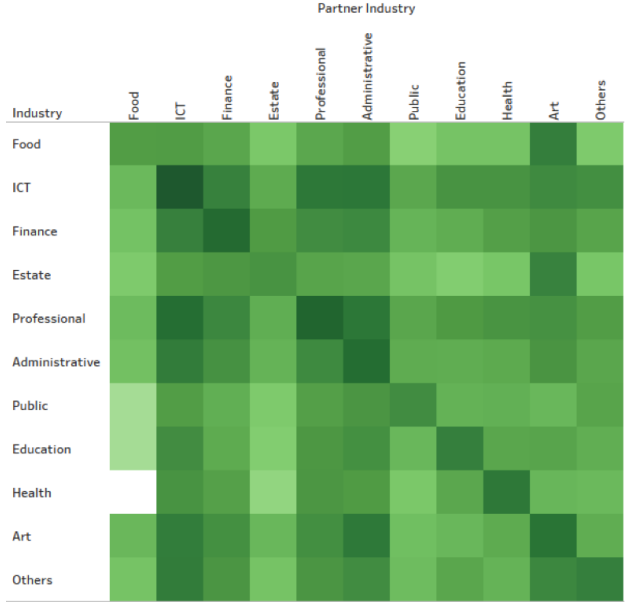

Figure 5. Service Industry Value Co-Creation.

While the individual visualizations of service industries provide comparable macroscopic insights into visible structural characteristics, it is important to determine whether there are any deeper commonalities and differences. To do so, we constructed a multidimensional feature vector of network level structure metrics for each service industry and computed the pairwise distances [34]. Details of how the feature vector was constructed and analyzed is provided in the online appendix (upon request). The objective is to determine whether and which industries exhibit similar topological interfirm collaboration characteristics Figure 6 shows the corresponding multidimensional scaling plot. The MDS reveals that in general service industries exhibit very different characteristics. ICT and Health are the most significant outliers. The two industries most similar to each other are Food and Education. Art, Administrative, and Professional appear to also be somewhat structurally similar. The most similar service industry to Public is Estate.

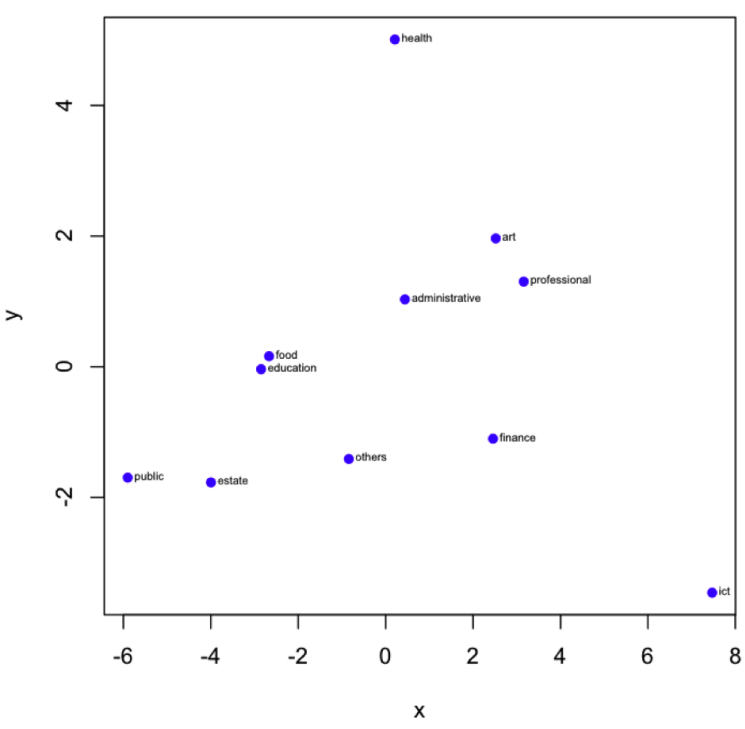

Figure 6. Structural Similarity of Service Industries.

\section{Discussion}

\subsection{The Coopetition/Exploration Spectrum}

Our results indicate that service industries cover a broad spectrum of value-seeking orientations, ranging from moderately coopetitive (e.g., ICT) to balanced (e.g., Finance) to strongly exploratory (e.g., Administrative). No single type of orientation dominates or stands out. At a high-level the results reveal that all industries employ a somewhat ambidextrous relationship model. Ambidexterity enables firms to adapt to rapid technological changes and market trends.

The heterogeneity of orientations also suggest that each service industry has its own relationship requirements, potentially demanding different exploratory and coopetitive strategies. Indeed, prior 


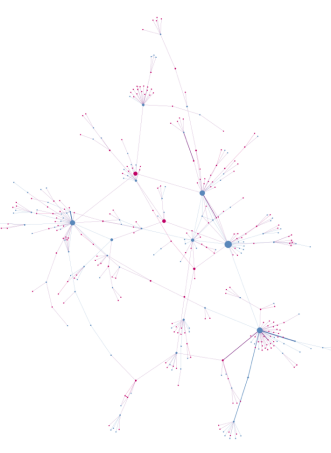

(a)

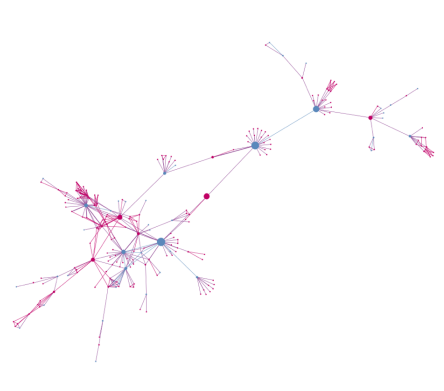

(d)

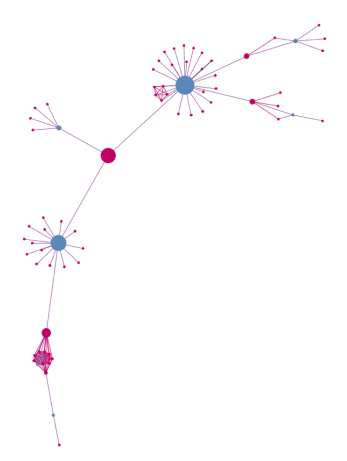

(g)

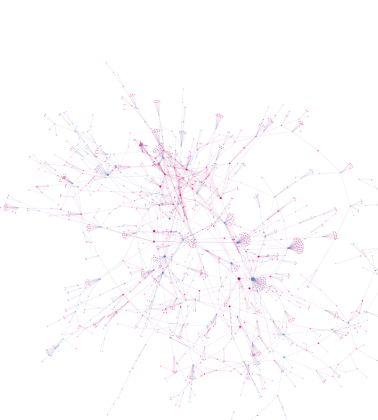

(j)

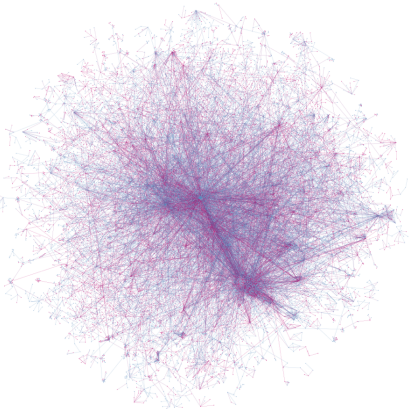

(b)

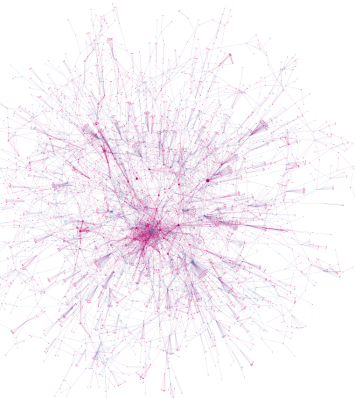

(e)

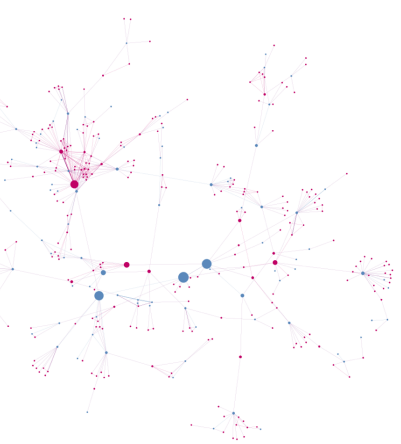

(h)

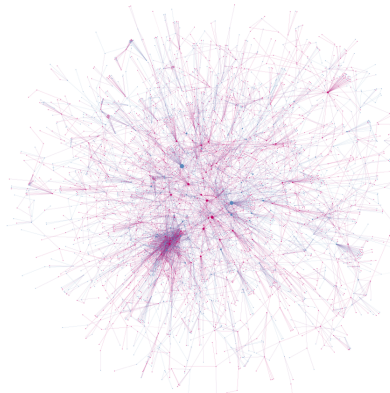

(c)

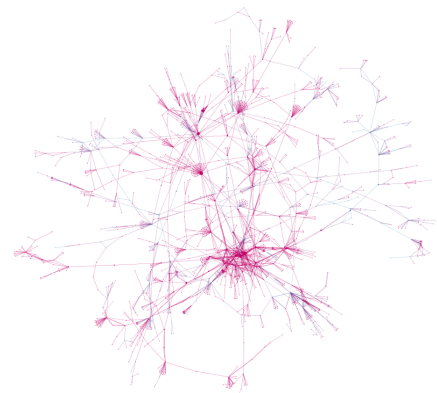

(f)

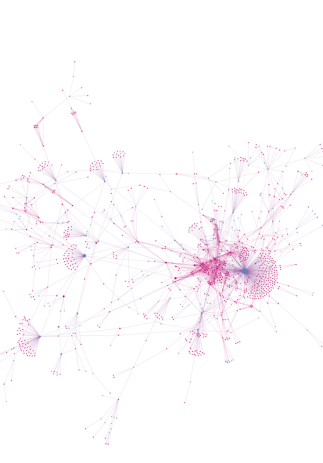

(k)

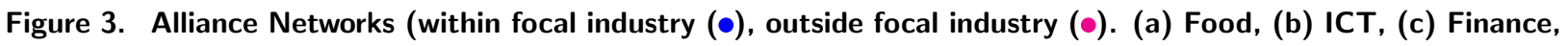
(d) Estate, (e) Professional, (f) Administrative, (g) Public, (h) Education, (i) Health, (j) Art, and (k) Others. 


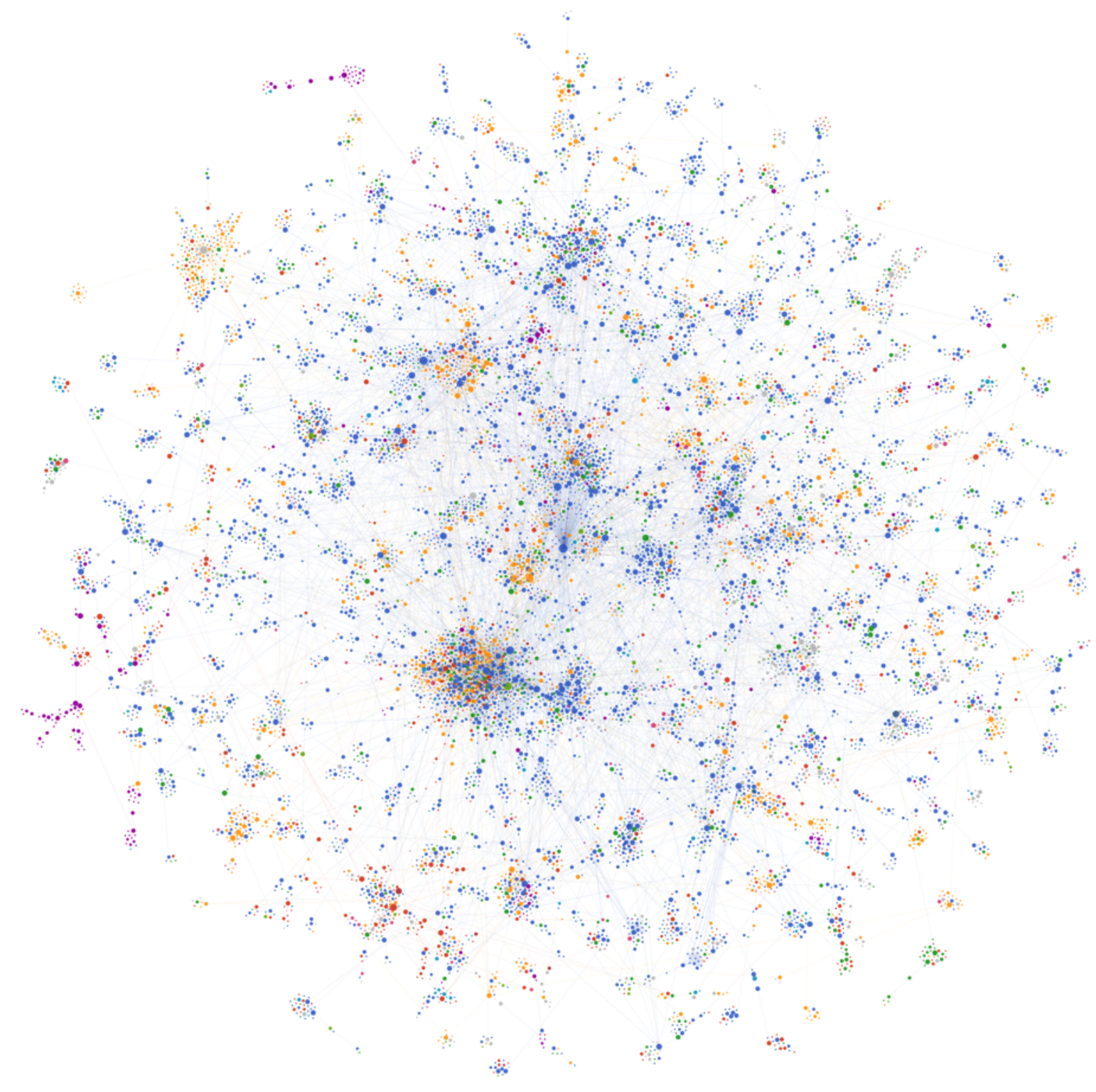

Figure 4. The macro alliance network of all service industries. The main component contains 27,350 firms (41.77\% visible) and 45,195 alliances (65.6\% visible). After filtering out non-services firms, the macro-services ecosystem consists of 11,702 firms $(17.89 \%)$ and 16,568 alliances $(23.91 \%)$. 
work has shown that the optimal balance varies across industries.

In stable or gradually changing business environments, where a dominant technological design may have emerged [35], firms can likely survive with incremental innovation strategies [36]. In such settings, ambidexterity may be less important. However, in more dynamic and competitive environments, firms may need to pursue higher levels of ambidexterity in order to innovate more radically.

While this may apply to our study context, some of our findings suggest something somewhat opposite. The ICT industry is broadly considered one of the more innovative of all service industries. Yet, it is leaning more coopetitive than exploratory. This may be to the fact that much of the relevant innovations needed to advance can be found within the industry rather than outside. On the other hand, industries that are rather slow to innovate are seeking opportunities outside their own, as evidenced by Administrative, Public, and Estate.

A balanced approach also suggests a more strategic, long-term oriented perspective on growth and performance. ICT and Health are two service industries that lean more towards coopetition, suggesting that near-term performance success is potentially more critical than long term exploratory relationships.

\subsection{Service Industry Embeddedness and Convergence}

No service industry is an island. Our analysis shows that there are relationships between all service industries, with some stronger than others. The ICT industry plays arguably the most central and prominent role in the macro service ecosystem. This is not surprising given the importance of technology to all aspects of service design, creation, and delivery.

Another observation from our macro analysis is that service industry boundaries are increasingly blurring. In the past, firms may have belonged to one or few well defined industries and perhaps collaborated only with few other industries. Today firms increasingly position themselves at the intersection of industries or are creating entirely new ones and are cross-pollinating relationships across many industries. This has several implications. First as existing industries are increasingly transformed it will become challenging to measure the economic impact of individual industries. New industry classifications will have to emerge. Second, identifying new value/innovation opportunities will by default now demand looking beyond traditional boundaries and relationships. Increasing shifts in boundaries also result in changing power structures, as incumbents are replaced either by new entrants or new competitors who form competitive ecosystems.

\subsection{Relationship Whitespaces}

Our analysis showed that there are different levels of coupling between industries, some stronger than others. In industry pairs where there is already very strong coupling, firms will likely continue to reinforce existing positive relationships and abandon any negative relationships. As value expectations and demands change these areas could lose in coupling strength in favor of other couplings. In areas of weak industry coupling, it can argued that novel and promising relationship white spaces exist. The reason for these white spaces could be twofold. One, no real value opportunity exists, either because there really is not any or because no one has pursued them. If the latter, these white spaces should be actively explored and pursued.

\subsection{Structural Robustness}

Almost all industries are likely to experience some level of disruption, either organically, through technology, or through external forces [37]. Some of these can be anticipated, while others can fundamentally alter the ecosystem [38]. An important measure of industry is thus its ability to withstand change. This ability can be measured using network robustness, which assesses how fragment a network may get when an increasing number of firms are removed. The higher the level of clustering, the more likely the network can absorb changes. Our results show that among our service industries, ICT and Health have the lowest levels of clustering, and thus probably are facing the greatest risk of disruption from a structural perspective. On the other hand, service industries like public, education, and art have significant clustering, thus structurally they are likely to be more resistant to change. This finding has to be taken with some caution, however, as changes are not such structural. Technological disruptions are going to impact all service industries, as we see in Finance and Administrative for instance [39]. Given the potential for digital transformation in these industries, it is likely that relationships will be altered as new players will enter.

\subsection{The Role of Technology}

As we mentioned above, one of the most striking results of our study is the central importance of the ICT industry to all other service industries. Technology helps firms gain efficiencies, identify new opportunities, enter new markets, scale operations, and prepare for threats and challenges. No industry is safe without embracing 
technology. While this may not be necessarily surprising it underlines the need for firms in other industries to be aware and have a clear strategy in regards to technology in general. As IT becomes more commoditized, there is a greater need to differentiate through new types of technologies and solutions. The advent of big data, analytics, AI, and blockchain is poised to transform all service industries. It is probably not far-fetched to argue that the competencies to pursue these promising technologies reside largely within the ICT industry. Indeed, many alliances/collaborations that are formed are with digital technology companies that often are important platform companies.

\section{Concluding Remarks}

In this study we examine the collaborative structure of service industries. Using a data-driven visualization approach, our results reveal significant structural differences in alliance network structures as well as diverse value co-creation orientations. Our macro analysis of all industries together reveals a core-periphery structure and different service industry coupling levels with the ICT industry playing a particularly central role across subclusters. We believe that our study provides an important understanding of the nature of collaborative value creation in service industries and offers insights into how open, robust, and embedded an industry is in the broader context.

While our analyses advance our understanding of service industries and interfirm value networks there are many avenues of research that could be pursued. It is clear that alliances are just one form of interfirm relationship. Other partnerships may also reveal important complementary insights. One particular extension includes the examination of the role of digital relationships between firms in service industries. It is argued that traditional relationships such as alliances are increasingly complemented or even replaced by more fluid and flexible digital relationships, such as APIs. An important examination then would include if and to what extent service industries are embracing APIs, which ones they are leveraging, and how this compares to the alliances network structures examined in this study. Some early work is presented by [40] but a differentiation by service industry has yet to occur. It is likely that such studies will further amplify the role of ICT companies in digital value creation, but also reveal the state of digitization across service industries.

In our study we used network-level metrics to determine service industry similarity. Future work could develop a more detailed feature vector of service industries, including network, node, and edge level features. We could also leverage a text analytic approach using company description to identify similar/dissimilar firms [41]. This may provide an alternate look at service industries clusters and boundaries.

\section{References}

[1] R. C. Basole, M. G. Russell, J. Huhtamäki, N. Rubens, K. Still, and H. Park, "Understanding business ecosystem dynamics: A data-driven approach," ACM Transactions on Management Information Systems, vol. 6, no. 2, p. 6, 2015.

[2] R. C. Basole and W. B. Rouse, "Complexity of service value networks: Conceptualization and empirical investigation," IBM Systems Journal, vol. 47, no. 1, pp. 53-70, 2008.

[3] W. B. Rouse and R. C. Basole, "Understanding complex product and service delivery systems," in Handbook of service science, pp. 461-480, Springer, 2010.

[4] S. L. Vargo and M. A. Akaka, "Value cocreation and service systems (re) formation: A service ecosystems view," INFORMS Service Science, vol. 4, no. 3, pp. 207-217, 2012.

[5] R. C. Basole, H. Park, and B. C. Barnett, "Coopetition and convergence in the ICT ecosystem," Telecommunications Policy, vol. 39, no. 7, pp. 537-552, 2015.

[6] R. C. Basole, S. Ghosh, and M. S. Hora, "Supply network structure and firm performance: Evidence from the electronics industry," IEEE Transactions on Engineering Management, vol. 65, no. 1, pp. 141-154, 2017.

[7] A. Grandori and G. Soda, "Inter-firm networks: antecedents, mechanisms and forms," Organization Studies, vol. 16, no. 2, pp. 183-214, 1995.

[8] R. Gulati, N. Nohria, and A. Zaheer, "Strategic networks," Strategic Management Journal, vol. 21, no. 3, pp. 203-215, 2000.

[9] C. Dhanaraj and A. Parkhe, "Orchestrating innovation networks," Academy of Management Review, vol. 31, no. 3, pp. 659-669, 2006.

[10] M. A. Schilling and C. C. Phelps, "Interfirm collaboration networks: The impact of large-scale network structure on firm innovation," Management Science, vol. 53, no. 7, pp. 1113-1126, 2007.

[11] R. Gulati, "Alliances and networks," Strategic Management Journal, vol. 19, no. 4, pp. 293-317, 1998.

[12] M. A. Schilling, "Understanding the alliance data," Strategic Management Journal, vol. 30, no. 3, pp. 233-260, 2009.

[13] W. W. Powell, K. W. Koput, and L. Smith-Doerr, "Interorganizational collaboration and the locus of innovation: Networks of learning in biotechnology," Administrative Science Quarterly, pp. 116-145, 1996.

[14] R. C. Basole, "Topological analysis and visualization of interfirm collaboration networks in the electronics industry," Decision Support Systems, vol. 83, pp. 22-31, 2016.

[15] S. Ili, A. Albers, and S. Miller, "Open innovation in the automotive industry," $R \& D$ Management, vol. 40, no. 3, pp. 246-255, 2010. 
[16] P. P. Maglio and J. Spohrer, "Fundamentals of service science," Journal of the Academy of Marketing Science, vol. 36, no. 1, pp. 18-20, 2008.

[17] J. C. Spohrer and P. P. Maglio, "Toward a science of service systems," in Handbook of Service Science, pp. 157-194, Springer, 2010.

[18] P. K. Chathoth and M. D. Olsen, "Strategic alliances: a hospitality industry perspective," International Journal of Hospitality Management, vol. 22, no. 4, pp. 419-434, 2003.

[19] C. Feng and K. Sivakumar, "The role of collaboration in service innovation across manufacturing and service sectors," INFORMS Service Science, vol. 8, no. 3, pp. 263-281, 2016.

[20] R. Rajala, F. Gallouj, and M. Toivonen, "Introduction to the special issue on multiactor value creation in service innovation: Collaborative value creation in service," INFORMS Service Science, vol. 8, no. 3, pp. iii-viii, 2016.

[21] A. Smedlund, "Value cocreation in service platform business models," INFORMS Service Science, vol. 4, no. 1, pp. 79-88, 2012.

[22] M. A. Cusumano, S. J. Kahl, and F. F. Suarez, "Services, industry evolution, and the competitive strategies of product firms," Strategic Management Journal, vol. 36, no. 4, pp. 559-575, 2015.

[23] R. Schmalensee, "Inter-industry studies of structure and performance," Handbook of Industrial Organization, vol. 2, pp. 951-1009, 1989.

[24] L. Rosenkopf and M. A. Schilling, "Comparing alliance network structure across industries: observations and explanations," Strategic Entrepreneurship Journal, vol. 1, no. 3-4, pp. 191-209, 2007.

[25] Y. Geum, M.-S. Kim, and S. Lee, "Service technology: Definition and characteristics based on a patent database," INFORMS Service Science, vol. 9, no. 2, pp. 147-166, 2017.

[26] A. Zaheer, E. Hernandez, and S. Banerjee, "Prior alliances with targets and acquisition performance in knowledge-intensive industries," Organization Science, vol. 21, no. 5, pp. 1072-1091, 2010.

[27] S. Wasserman and K. Faust, Social network analysis: Methods and applications, vol. 8. Cambridge University Press, 1994.

[28] M. Card, Readings in information visualization: using vision to think. Morgan Kaufmann, 1999.

[29] R. C. Basole, "Visualization of interfirm relations in a converging mobile ecosystem," Journal of Information Technology, vol. 24, no. 2, pp. 144-159, 2009.

[30] R. C. Basole, T. Clear, M. Hu, H. Mehrotra, and J. Stasko, "Understanding interfirm relationships in business ecosystems with interactive visualization," IEEE Transactions on Visualization and Computer Graphics, vol. 19, no. 12, pp. 2526-2535, 2013.

[31] B. R. Iyer and R. C. Basole, "Visualization to understand ecosystems," Communications of the ACM, vol. 59, no. 11, pp. 27-30, 2016.

[32] M. Bastian, S. Heymann, and M. Jacomy, "Gephi: an open source software for exploring and manipulating networks," in Third International AAAI Conference on Weblogs and Social Media, 2009.
[33] Y. Hu, "Efficient, high-quality force-directed graph drawing," Mathematica Journal, vol. 10, no. 1, pp. 37-71, 2005.

[34] G. Li, M. Semerci, B. Yener, and M. J. Zaki, "Effective graph classification based on topological and label attributes," Statistical Analysis and Data Mining: The ASA Data Science Journal, vol. 5, no. 4, pp. 265-283, 2012.

[35] J. M. Utterback and W. J. Abernathy, "A dynamic model of process and product innovation," Omega, vol. 3, no. 6, pp. 639-656, 1975.

[36] M. L. Tushman and C. A. O'Reilly III, "Ambidextrous organizations: Managing evolutionary and revolutionary change," California Management Review, vol. 38, no. 4, pp. 8-29, 1996.

[37] O. Abbosh, P. Nunes, and L. Downes, Pivot to the Future. Public Affairs, 2019.

[38] W. B. Rouse, Enterprise transformation: Understanding and enabling fundamental change, vol. 43. John Wiley \& Sons, 2006.

[39] P. R. Daugherty and H. J. Wilson, Human+ machine: reimagining work in the age of AI. Harvard Business Press, 2018.

[40] P. C. Evans and R. C. Basole, "Revealing the API ecosystem and enterprise strategy via visual analytics," Communications of the ACM, vol. 59, no. 2, pp. 26-28, 2016.

[41] R. C. Basole, H. Park, and R. O. Chao, "Visual analysis of venture similarity in entrepreneurial ecosystems," IEEE Transactions on Engineering Management, no. 99, pp. 1-15, 2018. 